\title{
Investigation of the many-particle spectrum of superconductor $\mathrm{YBa}_{2} \mathrm{Cu}_{3} \mathrm{O}_{7}$
}

\author{
G A R LIMA, A FAZZIO and R MOTA* \\ Instituto de Fisica da Universidade de São Paulo, CP 20516, 01498 São Paulo, SP. Brazil \\ * Departamento de Física-UFSM, 97119 Santa Maria, RS, Brazil
}

\begin{abstract}
We investigate the electronic structure of superconductor $\mathrm{YBa}_{2} \mathrm{Cu}_{3} \mathrm{O}_{7}$ through a molecular cluster approach. The calculations are performed self-consistently through a semi-empirical LCAO technique, and correlation effects are taken into account by a configuration interaction procedure (INDO-CI). Our results for the larger clusters yjeld a density of states (in the valence band) that is in good agreement with the experimental data. We obtain for the ground-state a strong $p-d$ covalency, resulting in a width of around $8 \mathrm{eV}$ for the valence band. The interactions of $\mathrm{Cu}(1)$ and (2) with $\mathrm{O}(1),(2),(3)$ and (4) are analysed, showing how hybridization occurs. In all cases we calculate the Mott-Hubbard energy $U$ taking into account many-body effects.
\end{abstract}

Keywords. Many particle spectrum; electronic structure; molecular cluster approach.

\section{Introduction}

In the past few years considerable effort has been devoted to an understanding of the transport properties of the oxide superconductors. On the theoretical side, the effort motivated a large number of electronic structure calculation for typical compounds (Pickett 1989). Even so there is at present no complete comprehensive theory for the mechanism of high-temperature superconductivity in these materials. In particular the compound $\mathrm{YBa}_{2} \mathrm{Cu}_{3} \mathrm{O}_{7}$, which presents a transition temperature above $90 \mathrm{~K}$ (Wu et al 1987), is characterized by chain and quasi-planar structure of alternated $\mathrm{Cu}-\mathrm{O}$ atoms and the precise role of these structure remains unclear.

Here we study the electronic structure of models corresponding to a chain $(\mathrm{O}(1), \mathrm{Cu}(1), \mathrm{O}(4))$ and a plane (contuining $\mathrm{O}(2), \mathrm{Cu}(2)$ and $\mathrm{O}(3))$ as shown in figure 1. Most of the previous electronic structure calculations have been based on the spin-density functional formalism, which does not include electronic correlation (Chen et al 1988). The present work attempts to incorporate correlation effects in the electronic structure results. To do that we adopt the finite cluster approach: appropriate clusters are chosen, and a sophisticated semi-empirical technique is used to solve the Hartree-Fock-Roothaan equations. The self-consistent ground-state molecular orbitals $\varphi_{i}$ are used to write the many-electron wave-function in a configuration interaction $(\mathrm{CI})$ procedure as

$$
\phi_{\Gamma}=\sum_{k=1}^{\phi} C_{k}^{\Gamma} \psi_{k},
$$

where each $\psi_{k}$ is a Slater determinational function corresponding to a particular orbital configuration and the $\varphi_{i}$ 's are built in terms of atomic functions $\chi_{\mu}$

$$
\varphi_{i}=\sum_{\mu} b_{i \mu} \chi_{\mu} .
$$




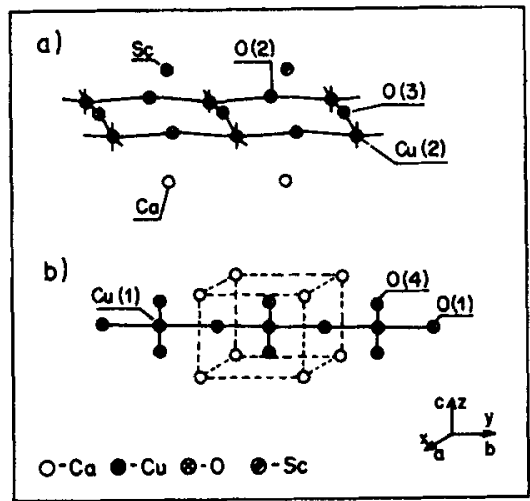

Figure 1. (a) $\mathrm{Sc}_{2} \mathrm{Ca}_{2} \mathrm{Cu}_{6} \mathrm{O}_{7}$ quasi-planar case. (b) $\mathrm{Ca}_{8} \mathrm{Cu}_{3} \mathrm{O}_{10}$ chain case.

We use the INDO (intermediate neglect of differential overlap) technique (Bacon and Zerner 1978) for building the Fock operator in

$$
\mathbf{F b}=\mathbf{b} \varepsilon,
$$

where $\mathbf{F}=\mathbf{H}+\mathbf{J}+\mathbf{K}$ includes the one-electron hamiltonian $\mathbf{H}$, the direct Coulomb term $\mathbf{J}$ and the exchange $\mathbf{K}$. The basis set comprises Clementi single-zeta orbitals: $s$ and $p$ for $\mathrm{O}$ and $s, p, d$ for heavier atoms.

\section{Results and discussion}

We have studied several clusters differing in size. To avoid difficulties in parametrization, the $\mathrm{Ba}$ and $\mathrm{Y}$ atoms of the original compound are replaced in our calculation by the isoelectronic $\mathrm{Ca}$ and $\mathrm{Sc}$ atoms at the same crystallographic sites. Two of the studied clusters are shown in figure 1 corresponding to (a) the quasi-planar case $\left[\mathrm{Sc}_{2} \mathrm{Ca}_{2} \mathrm{Cu}_{6} \mathrm{O}_{7}\right]$ and (b) the chain cases $\left[\mathrm{Ca}_{8} \mathrm{Cu}_{3} \mathrm{O}_{10}\right]$.

We chose as the appropriate charge state for the compound that where the $4 s$ states of the $\mathrm{Ca}$ and $\mathrm{Sc}$ atoms are almost empty, acting as electron donors to the rest of the crystal. In this case, the oxidation states are $6+$ and $5+$ for quasi-planar and chain case respectively.

The valence-electron charge of the atoms in the cluster is discussed using Mulliken's population analysis in terms of atomic states $(s, p, d)$ as shown in table 1 . For the cluster $\left[\mathrm{Ca}_{8} \mathrm{Cu}_{3} \mathrm{O}_{10}\right]$ results in a formal valence charge of +1.15 and for the $\left[\mathrm{Sc}_{2} \mathrm{Ca}_{2} \mathrm{Cu}_{6} \mathrm{O}_{7}\right]$, cluster results are $+1 \cdot 12$. The conclusions that can be drawn from these values are that $\mathrm{Cu}^{3+}$ is not found as pointed out by Horn et al (1987), and that $\mathrm{Cu}$ is in a fluctuating state between $1+$ and $2+$.

In the cluster $\left[\mathrm{Sc}_{2} \mathrm{Ca}_{2} \mathrm{Cu}_{6} \mathrm{O}_{7}\right]$, detailed studies of the upper occupied orbitals show a shared contribution from $\mathrm{O}_{p y}$ and $\mathrm{Cu}_{d_{x}{ }^{2}-y^{2}}$ states through a strong hybridization. In the cluster $\left[\mathrm{Ca}_{8} \mathrm{Cu}_{3} \mathrm{O}_{10}\right]$ chain, there appears also, in the upper occupied orbitals, a strong hybridization of $\mathrm{O}(1)$ py and $\mathrm{O}(4) \mathrm{pz}$ states with $\mathrm{Cu}_{d_{x^{2}-y^{2}}}$ and $\mathrm{Cu}_{d_{z}{ }^{2}}$ states, with a dominance contribution from $\mathrm{O}$ states in this case, which is in agreement with 
Table 1. Valence population analysis in the Mulliken approximation for the clusters $\mathrm{Ca}_{8} \mathrm{Cu}_{3} \mathrm{O}_{10}$ (chain) and $\mathrm{Sc}_{2} \mathrm{Ca}_{2} \mathrm{Cu}_{6} \mathrm{O}_{7}$ (plane) atoms are labelled according to figure 1 .

\begin{tabular}{|c|c|c|c|c|c|c|c|c|c|c|}
\hline & \multicolumn{6}{|c|}{ Mulliken population } & \multirow[b]{2}{*}{$\mathbf{O}^{s}(3)$} & \multirow[b]{2}{*}{$\mathrm{O}^{p}(3)$} & \multirow[b]{2}{*}{$\mathrm{O}^{s}(4)$} & \multirow[b]{2}{*}{$O^{\prime}(4)$} \\
\hline & $\mathrm{Cu}^{s}$ & $\mathrm{Cu}^{d}$ & $O^{s}(1)$ & $\mathrm{O}^{p}(1)$ & $\mathrm{O}^{s}(2)$ & $\mathrm{O}^{p}(2)$ & & & & \\
\hline $\begin{array}{l}\mathrm{Ca}_{8} \mathrm{Cu}_{3} \mathrm{O}_{10} \\
\mathrm{Sc}_{2} \mathrm{Ca}_{2} \mathrm{Cu}_{6} \mathrm{O}_{7}\end{array}$ & $\begin{array}{l}0.36 \\
0.19\end{array}$ & $\begin{array}{l}9.56 \\
9.52\end{array}$ & $2 \cdot 00$ & $5 \cdot 11$ & 1.96 & 4.89 & 1.95 & 5.05 & 2.00 & $5 \cdot 23$ \\
\hline
\end{tabular}

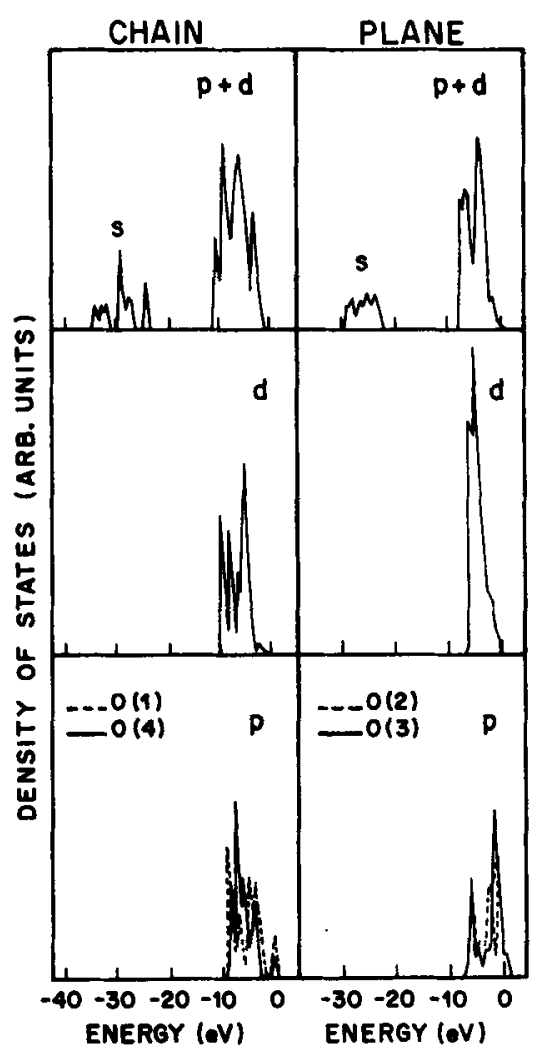

Figure 2. Comparison of results for the density-of-states of clusters $\mathrm{Ca}_{8} \mathrm{Cu}_{3} \mathrm{O}_{10}$ (chain) and $\mathrm{Sc}_{2} \mathrm{Ca}_{2} \mathrm{Cu}_{6} \mathrm{O}_{7}$ (plane). Top: total electronic density of states, middle: partial density of states for $\mathrm{Cu}_{d}$, bottom: partial density of states for $\mathrm{O}_{p}$. The Fermi energy has been chosen as the zero of the energy scale.

the assumption that the $\mathrm{O}_{p}$ holes play an important role in the conduction mechanism (Stechel and Jennison 1988; Emery 1987).

We show in figure 2 the total and partial density for the studied clusters. It is clear from the figure that the valence band is mainly composed of $\mathrm{Cu}_{d}$ and $\mathrm{O}_{p}$ states having bandwidths around $7 \mathrm{eV}$ for the plane and $6 \mathrm{eV}$ for chain.

The Mott-Hubbard parameter $U$ which measures the intra-atomic energy between electron $(p$ and $d)$ on $\mathrm{O}$ and $\mathrm{Cu}$ sites respectively is estimated including correlation 
effects. In this case the spectra for the clusters are obtained using up to 180 Slater determinantal functions, $\phi_{\Gamma}$ in equation (1) is built with single and double excitations from the Hartree-Fock using the last 10 orbitals occupied with $p$ and $d$ character through the first 4 unoccupied orbitals with the same character. The value we obtain are: for $\left[\mathrm{Sc}_{2} \mathrm{Ca}_{2} \mathrm{Cu}_{4} \mathrm{O}_{7}\right] U=3.40 \mathrm{eV}$ and for $\left[\mathrm{Ca}_{8} \mathrm{Cu}_{3} \mathrm{O}_{10}\right] U=2 \cdot 37$. Even our Hartree-Fock calculation presents values for $U$ smaller than that obtained by Chen et al (1987). In general our results differ in magnitude from that obtained by the works cited before.

\section{Conclusions}

In this paper we perform self-consistent calculations including correlation effects for different clusters representing the $\mathrm{YBa}_{2} \mathrm{Cu}_{3} \mathrm{O}_{7}$ compound. The density-of-states and bandwidths we obtain for the $\mathrm{O}_{p}$ and $\mathrm{Cu}_{d}$ bands are in general agreement with previous studies. We may summarize the main conclusions as: (i) significant valence fluctuation occurs between the $\mathrm{Cu}\left(d^{9}\right)$ and $\mathrm{Cu}\left(d^{10}\right)$ configurations, (ii) analysis of the upper occupied orbitals corroborates the assumption that $\mathrm{O}_{p}$ holes contribute to the conduction mechanism, and (iii) the values for the Mott-Hubbard energy decrease with inclusion of correlation effects.

\section{References}

Bacon A D and Zerner M C 1978 Theor. Chim. Acta $\mathbf{5 3} 21$

Chen H, Callawoy J and Misra P K 1988 Phys. Rev. B38 195

Emery V J 1987 Phys. Rev. Lett. 58 26, 2794

Horn S, Cau J, Shaheen S A, Jeon Y, Croff M, Chang C L and den Boer M L 1987 Phys. Rev. B36 3895

Pickett W E 1989 Rev. Mod. Phys. 612,433

Stechel E B and Jennison D R 1988 Phys. Rev. B38 4632

Wu M K, Astibunz J R, Torny C J, Hor P H, Meng R L, Gao L, Huang Z J, Wang Y Q and Chu C W 1987 Phys. Rev. Lett. 58908 